\title{
Evidence of intra-chain phase separation in molten short-chain branched polyethylene
}

\author{
F. J. Stadler* \\ Chonbuk National University, School of Semiconductor and Chemical Engineering, 664-14, 1-ga Deokjin-dong, \\ Deokjin-gu, Jeonju, Jeonbuk, 561-756, Republic of Korea
}

Received 9 September 2010; accepted in revised form 8 November 2010

\begin{abstract}
Intramolecular phase separation is usually associated with block-copolymers, but the same phenomenon is also obtainable by random-copolymers. In this article, evidence of intramolecular phase separation is reported for a linear octadecene-ethene copolymer, which shows an evolving 'yield point' at a long time and low frequency. This is attributed to a partial phase separation of the long short-chain branches. In creep recovery, this behavior is evident as increasing elastic steady-state creep recovery compliance $J_{\mathrm{e}}{ }^{0}$. In contrast to 'normal' block-copolymers, this special polymer has an increase in phase separation with temperature, which is caused by the chemical composition and the short chain segments in the side chain domain, leading to a high surface fraction.
\end{abstract}

Keywords: rheology, phase separation, linear low density polyethylene, time-temperature superposition

\section{Introduction}

The question whether two polymers can be blended together is one of the oldest in the history of polymer science, which primarily comes from the question of whether the usual endothermic heat of mixing and the very small combinatorial entropy of mixing make a phase separation thermodynamically favorable. The usual case is the immiscibility of two polymers $[1,2]$. Although polyolefins (e.g. polyethylene and polypropylene) are very similar in their molecular structure, they are known to be immiscible [3]. Also blends of polyethylene and ethylene-/ $\alpha$-olefin copolymers are known to be phase separating under certain conditions, which highlights the fact that rather small chemical differences can already lead to phase separation, although it is reported to be rather weak [4-8]. While two polymers in a blend have to be mixed physically, it is also possible to link them together chemically to form di- or multiblock copolymers. On a nano scale, this also leads to phase separation, whose size naturally is determined by the molar masses of the individual blocks $[9,10]$. This effect differs from blending in the way that it only involves one species of polymers; hence, it is an intrachain phase separation as opposed to a normal (interchain) phase separation. Kossuth et al. [11] published an overview of the rheological behavior classified by their terminal behavior in the angular frequency dependent storage modulus $G^{\prime}(\omega)$. In general, the better ordered, the lower the terminal slope of $G^{\prime}(\omega)$. Cubic phases - the maximum ordered state - don't flow at all, while a disordered state leads to a pattern very similar to a normal polymer melt [12]. Recently, Park et al. [13] established that such behavior can also be observed in ethylene/octene-block-ethylene/octenecopolymers, whose blocks differ distinctly in comonomer concentration. This shows that even small chemical differences suffice to create a biphasic structure. However, they didn't give the block

\footnotetext{
${ }^{*}$ Corresponding author, e-mail: fjstadler@jbnu.ac.kr
} (c) BME-PT 
length in their paper, as it cannot be determined due to the synthesis method.

Such block-copolymers are usually thermorheologically complex $[9,14,15]$. The group of Bates [9, 10], for example, found that below the order-disorder transition temperature, i.e., in the ordered state, the sample behaves like a gel and thermorheologically simple, while in the disordered state, a clear thermorheological complexity is found. The higher the temperature, the less pronounced the long-term relaxation process and, thus, the more similar is the data to a single-phase polymer melt.

Recently, it was also proven that pure ethylene- $/ \alpha$ olefin copolymers with very long comonomers (C26) can be phase separating in the solid state, if their comonomer content is sufficiently high [16]. This effect is different from the previous cases, because it only involves one type of chain and, furthermore, occurs on random copolymers. Hence, it is an effect that occurs only on a short length scale, as shown by the fact that the length of the comonomers used were 18 and 26 carbons. Thus, the second phase has to encompass only the maximum of 24 terminal carbons; realistically, 16-20 carbons. This effect had a small trace in X-ray diffraction, which points to a weak side chain crystallization $[17,18]$. However, it was shown that the samples showing this phase behavior in the solid state [16] did not show it in the melt state, as the samples behaved like normal linear low density polyethylenes (LLDPEs), being only special because of their higher flow activation energy $E_{\mathrm{a}}$, which is the consequence of the side-chain content $s_{\mathrm{c}}$ of the comonomer [19, 20].

Phase separation in the melt is usually visible by traces of the interfacial tension [21] and different temperature dependencies of the individual blend components and the interfacial processes [22, 23]. Hence, if other techniques don't show any trace, e.g., because of too low differences in the electron density in X-ray scattering, rheological behavior can provide a valuable aid to the characterization of phase separation.

Recently, molecular dynamics studies revealed that samples with significant levels of short-chain branching indeed tend to form separate phases, which affirms above observations [24, 25].

The thermorheological complexity of single phase melts was not often investigated until about 10 years ago. This is in part the consequence of its rare occurrence in commercially available products before the introduction of long-chain branched metallocene catalyzed polyethylene (LCB-mPE) in the market, and also caused by the fact that thermorheological complexity is not easy to detect in the double logarithmic plot of the complex modulus $G^{\prime}(\omega)$ and $G^{\prime \prime}(\omega)$, especially, if only a relatively small frequency and temperature range is covered [24-26]. Also, the thermorheological complexity can be partially masked by a broad molar mass distribution $(M M D)$, which causes the different relaxation processes to be smeared out [26]. Low density polyethylene (LDPE), for example, has a thermorheological complexity, which can be eliminated by an arbitrary modulus shift, whose origin remains to be determined [26-28]. Currently, it can only be said that the modulus shift $b_{\mathrm{T}}$ for low density polyethylene (LDPE) follows an Arrhenius-temperature dependence which is 3-4 times stronger than expected from the density difference. The physical origin of this behavior is totally illusive at the moment, but different from LCB-mPE, because, unlike for LCB$\mathrm{mPE}$, the shape of $\delta(\omega)$ is not temperature dependent for LDPE [27, 28]. Only recently, viable analysis schemes for thermorheological complexity have become available [26, 27, 29-32]. The thermorheological complexity of long-chain branched metallocene PE leads to an increase of the activation energy towards longer relaxation times/lower relaxation strengths [29-31]. A similar effect was also found for long-chain branched polypropylenes (PP) and flouropolymers [27, 28, 32, 33]. The base of these methods is to determine the activation energy locally, i.e. at a given frequency, relaxation time, modulus, or relaxation strength, or to find out which quantity reacts insensitive to the thermorheological complexity, e.g., $\delta(\omega)$ is insensitive to the thermorheological complexity in LDPE and can, thus, be used for determining the 'real' activation energy [27, 28]. If no long-chain branching is present, any single phase melt shows thermorheological simplicity, i.e., the fulfillment of the tTS-principle (time-temperature superposition).

This article attempts to answer the question of whether the phase separation observed in the solid state for special ethylene-/ $\alpha$-olefin copolymers can also be observed in the melt, where side-chain crystallization cannot be the driving force. 


\section{Materials and methods}

\subsection{Materials}

The mLLDPE F18G is a linear ethene-octadecene copolymer, synthesized by B. Arikan (University Hamburg, Prof. Kaminsky) using the catalyst $\left[\mathrm{Ph} 2 \mathrm{C}\left(2,7-\right.\right.$ di $\left.\left.^{\text {tert }}{ }^{\text {BuFlu}}\right)(\mathrm{Cp})\right] \mathrm{ZrCl}_{2} / \mathrm{MAO}$ (University Hamburg, Hamburg, Germany). The synthesis of similar products was previously described [34, 35]. The product was stabilized with $0.5 \mathrm{wt} \%$ Irganox 1010 and 0.5 wt.\% Irgafos 168 (Ciba, Basel, Switzerland). L4 and C4 were commercial grades and were used as is [19].

\subsection{Molecular characterization}

The comonomer content of sample F18G (cf. Table 1) was measured by solution NMR using the WALTZ16-program [16]. For L4, melt-state NMR was used $[36,37]$.

Molar mass measurements were carried out by means of a high temperature size exclusion chromatograph (Waters, 150C) equipped with refractive index (RI) and infra-red (IR) (PolyChar, IR4) detectors. All measurements were performed at $140^{\circ} \mathrm{C}$ using 1,2,4-trichlorobenzene (TCB, Sigma-Aldrich, Schnelldorf, Germany) as the solvent. The high temperature size exclusion chromatograph (SEC) was coupled with a multi-angle laser light scattering (MALLS) apparatus (Wyatt, DAWN EOS). Details of the experimental SEC-MALLS set-up and the measuring conditions were previously published elsewhere [38].

The thermal behavior was measured on samples of about $10 \mathrm{mg}$ by differential scanning calorimetry (DSC) (TA Instruments, DSC 2920) using the maximum of the melting peak at a heating rate of $10 \mathrm{~K} / \mathrm{min}$ for the determination of the melting point.

\subsection{Rheology}

Samples were hot pressed into $25 \mathrm{~mm}$ diameter disks with $1 \mathrm{~mm}$ height at $180^{\circ} \mathrm{C}$ in vacuum for 5 min [38].

The shear rheological tests were carried out with a Bohlin Gemini air bearing and a TA Instruments AR-G2 magnetic bearing rheometer. Dynamicmechanical tests were carried out in the frequency range between 628 and $0.01 \mathrm{~s}^{-1}$ in the linear viscoelastic regime with a stress $\hat{\tau}$ between 10 and $50 \mathrm{~Pa}$, which yielded identical results in the com- plete frequency range. Hence, the linear viscoelastic range extends to at least this value, which corresponds to $\gamma_{0} \approx 5 \%$ at $\omega=0.01 \mathrm{~s}^{-1}$. Using higher strains will lead to a deviation mainly at low frequencies (cf. Figure 8). Creep and creep recovery tests were also performed in the linear viscoelastic regime with stresses between 2 and $20 \mathrm{~Pa}$.

The zero shear-rate viscosity $\eta_{0}$ was determined from the creep compliance, which can be deconvoluted as $J\left(t^{\prime}\right)=J_{0}+\psi\left(t^{\prime}\right)+\mathrm{t}^{\prime} / \eta_{0}$. As $J_{0}+\psi\left(t^{\prime}\right)=$ constant $\left(\rightarrow J_{\mathrm{e}}^{0}\right)$ for $t \rightarrow \infty$, obtaining $\eta_{0}$ is possible as soon as $J_{0}+\psi\left(t^{\prime}\right)<<t / \eta_{0}$. This is independent of the condition for the stationarity in the creep recovery test $J_{0}+\psi\left(t^{\prime}\right)=c=J_{\mathrm{e}}^{0}$ (for creep time $t_{0} \rightarrow \infty$ and shear stress $\tau \rightarrow 0$ ). Hence, obtaining $\eta_{0}$ is possible after significantly shorter creep times than $J_{\mathrm{e}}^{0}$. The exact definitions of the quantities discussed here are given in previous publications [29, 39].

All tests were performed in a nitrogen atmosphere between 110 and $230^{\circ} \mathrm{C}$. A frequency sweep (a dynamic mechanical test, in which the angular frequency is varied) in the beginning and at the end of the measurements of each sample was performed, to prove that no thermal degradation took place during the test. A maximum deviation of $\pm 5 \%$ between those two tests was considered to be acceptable. Also, a repetition of the test at $130^{\circ} \mathrm{C}$ was performed after all tests above $190^{\circ} \mathrm{C}$ to ensure the reversibility of the effect.

Relaxation spectra were calculated from the data using the method of Stadler and coworkers [40, 41].

\section{Results}

\subsection{SEC-MALLS}

Figure 1 shows the SEC-MALLS-data for the metallocene catalyzed linear low density polyethylenes (mLLDPE) L4 and F18G. The molar mass peak of F18G is slightly higher in $M_{\mathrm{LS}}$, which is also reflected in the higher molar mass of F18G (cf. Table 1). It is obvious that both materials have a similar, and narrow, molar mass distribution of $M_{\mathrm{w}} / M_{\mathrm{n}}=2$. F18G seems to be even a little bit narrower in molar mass distribution than L4. C4 is broader in molar mass distribution, which is why it will be mainly discussed with respect to its thermorheological behavior.

The SEC-MALLS-data of both materials show no deviation from the linear reference within the accuracy of the experiment, which points to the fact that 
Table 1. Rheological and molecular characteristics

\begin{tabular}{|l|c|c|l|c|c|c|c|c|}
\hline \multirow{1}{|c|}{$\#$} & $\begin{array}{c}\mathbf{M}_{\mathbf{w}} \\
{[\mathbf{k g} / \mathbf{m o l}]}\end{array}$ & $\begin{array}{c}\mathbf{M}_{\mathbf{w}} / \mathbf{M}_{\mathbf{n}} \\
{[-]}\end{array}$ & Comonomer & $\begin{array}{c}\mathbf{n}_{\mathbf{c}} \\
{[\mathbf{m o l} \mathbf{0}]}\end{array}$ & $\begin{array}{c}\mathbf{w}_{\mathbf{c}} \\
{[\mathbf{w t .} \% \mathbf{0}]}\end{array}$ & $\begin{array}{c}\mathbf{T}_{\mathbf{m}} \\
{\left[{ }^{\circ} \mathbf{C}\right]}\end{array}$ & $\begin{array}{c}\boldsymbol{\eta}_{\mathbf{0}}\left(\mathbf{T}=\mathbf{1 5 0}^{\circ} \mathbf{C}\right) \\
{[\mathbf{P a} \cdot \mathbf{s}]}\end{array}$ & $\begin{array}{c}\boldsymbol{\eta}_{\mathbf{0}} / \boldsymbol{\eta}_{\mathbf{0}}^{\text {lin }} \\
{[-]}\end{array}$ \\
\hline F18G & 140 & 1.9 & octadecene & 4.4 & 29.3 & ca. 75 & 9100 & 0.30 \\
\hline L4 & 114 & 2.0 & butene & 6.8 & 12.7 & $95[42]$ & 14000 & 1.03 \\
\hline C4 & 216 & 3.0 & - & 0.0 & 0.0 & $134[42]$ & 113000 & 0.78 \\
\hline
\end{tabular}

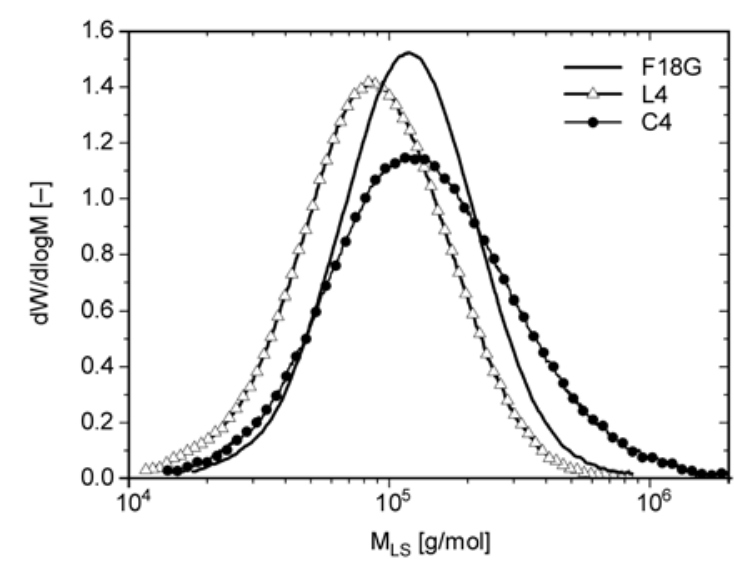

Figure 1. Molar mass distribution of C4, L4, and F18G

neither material contains any long-chain branching (see Ref. [43] for an in-depth discussion of the question of how long-chain branching can be detected in PE).

Table 1 shows the molecular characteristics of the samples characterized. For all samples in this article no long-chain branching was found.

\subsection{DSC}

The DSC-traces of the samples are given in Figure 2. While the mHDPE C4 and mLLDPE L4 show the expected traces of a narrow melting peak, F18G shows a broad peak, which can be described as roughly bimodal. This indicates fundamental differences in the crystalline structure. This structure was discussed by Pérez et al. [43], who found very similar DSC-traces for their sample. Based on their

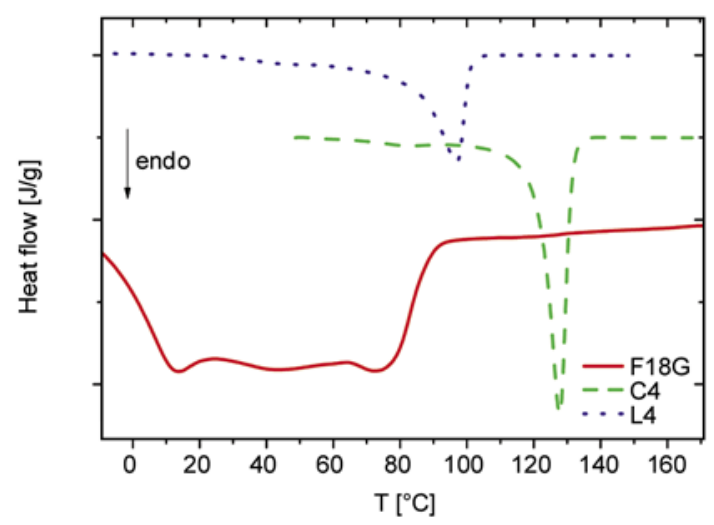

Figure 2. DSC-traces of C4, L4, and F18G (heating, $q=$ $20 \mathrm{~K} / \mathrm{min}$ ) results, they concluded that the octadecene sidechains do not crystallize themselves separately, which is in accordance with Piel et al. [16], who didn't find side-chain crystallization by DMTA. However, it is clear from the DSC-traces that the hexadecane side chains (formed by the octadecene) have to be somehow included into the main crystallites, which then leads to distorted low melting crystallites. The lower end of the melting area around $10^{\circ} \mathrm{C}$ roughly corresponds to the melting point of pentadecane, which means that probably the shortchain branches are located in higher concentrations (i.e. domains) locally and, thus, form some distorted crystals with some main chains in it.

Furthermore, it is obvious that the melting temperature of L4 is significantly higher than $T_{\mathrm{m}}$ of $\mathrm{F} 18 \mathrm{G}$ despite the fact that $\mathrm{L} 4$ contains approximately $70 \%$ more comonomer (in mol\%).

Although solid-state properties are not the main focus of the article, these findings already demonstrate that F18G is a special material despite the fact that it is only an LLDPE with longer comonomer.

\subsection{Rheology}

\subsubsection{Zero shear-rate viscosity $\eta_{0}$}

The first question needing to be answered is whether F18G is long-chain branched, as this would make the interpretation of the results significantly more complicated. However, the presence of sizable amounts of long-chain branches can also be safely excluded as the reaction conditions, under which F18G was synthesized inhibit the formation of long-chain branches [36]. Also the value of the zero shear-rate viscosity $\eta_{0}$ of about $9100 \mathrm{~Pa} \cdot \mathrm{s}\left(\right.$ at $150^{\circ} \mathrm{C}$ ) and the molar mass $M_{\mathrm{w}}$ of $140 \mathrm{~kg} / \mathrm{mol}$ make the presence of a small amount of LCBs very unlikely, as the expected zero shear-rate viscosity $\eta_{0}^{\text {lin }}$ at $140 \mathrm{~kg} / \mathrm{mol}$ is $30000 \mathrm{~Pa} \cdot \mathrm{s}$ [38]. Hence, the zero shear-rate viscosity increase factor $\eta_{0} / \eta_{0}^{\operatorname{lin}}$ is 0.3 , i.e. F18G is under the $\eta_{0}-M_{\mathrm{w}}$-relation for HDPE, which would mean that it is either of a different molecular structure (this is not the case, as the exact synthesis conditions and the NMR spectra clearly indicate it 
is an LLDPE) or highly branched (which can be excluded from SEC-MALLS and the synthesis conditions [36]). For LCB-mPEs, values of $\eta_{0} / \eta_{0}^{\text {lin }}$ between 2 and 1000 are usually found [35, 36, 4448]. Only for a very low molecular LCB-mHDPE $\left(M_{\mathrm{W}}=28 \mathrm{~kg} / \mathrm{mol}\right)$ an $\eta_{0} / \eta_{0}^{\text {lin }}<1$ was found [49].

Hence, it can be concluded that the standard indicator of long-chain branching, the zero shear-rate viscosity increase factor $\eta_{0} / \eta_{0}^{\text {lin }}$, is not in accordance with conventional polymers, but it definitely does not point to long-chain branching. Also, SEC-MALLS suggests a linear structure.

The zero shear-rate viscosity increase factor $\eta_{0} / \eta_{0}^{\text {lin }}$ of below 1 might be a consequence of the significant amount ( $4.5 \mathrm{~mol} \%$ ) of the rather long comonomer octadecene. This is in accordance with Wang et al. [50], who found a significant decrease of $\eta_{0}$ for longer poly- $\alpha$-olefins in comparison to PE. However, it remains puzzling why the sample F26F [51] has almost the same weight comonomer content $w_{\mathrm{c}}$ (having fewer but longer butacosene (C24) side chains) yet obeys the $\eta_{0}-M_{\mathrm{w}}$-correlation of HDPE [38].

Because an explanation requires the full presentation of the rheological behavior of $\mathrm{F} 18 \mathrm{G}$, it is moved to the discussion section.

\subsubsection{Elastic behavior}

Figure 3 shows the creep and creep recovery data of F18G. While the creep compliances $J\left(t^{\prime}\right)$ with $t_{0}=$ 415 and $4150 \mathrm{~s}$ agree very well, it becomes immediately obvious that the terminal value of the recoverable compliance $J_{\mathrm{r}}(t)$, the elastic recovery compli-

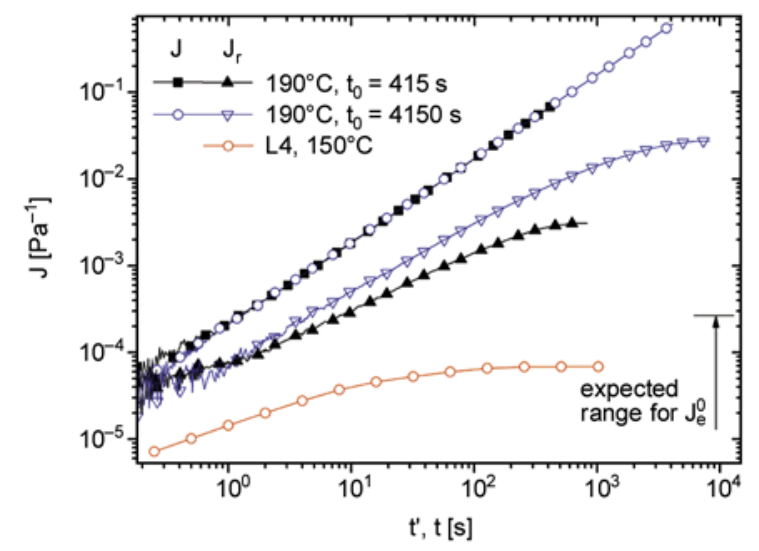

Figure 3. Creep and creep recovery compliance at $190^{\circ} \mathrm{C}$ for different creep times in the instationary regime. The linear and stationary creep recovery data of L4 is given in this figure for comparison [55]. ance $J_{\mathrm{e}}$, is very much dependent on the creep time $t_{0}$ (and also on the creep stress $\sigma_{0}$, which was not investigated here, as all creep experiments were carried out in the linear viscoelastic regime) [52]. The elastic recovery compliance $J_{\mathrm{e}}$ also exhibits a significantly higher value than comparable mLLDPEs, which have values for the steady-state elastic recovery compliance $J_{\mathrm{e}}^{0}$ around $10^{-4} \mathrm{~Pa}^{-1}$, i.e., $J_{\mathrm{e}}^{0}$ for F18G is more than a factor of 100 higher than that found for conventional LLDPEs (e.g. L4 in Figure 3). Please note that elastic recovery compliance $J_{\mathrm{e}}$ is smaller or equal than the steady-state elastic recovery compliance $J_{\mathrm{e}}^{0}$, as for the former, no proof of stationarity could be conducted. This was found to be impossible for $\mathrm{F} 18 \mathrm{G}$ due to the long terminal relaxation times (for a conventional LLDPE the terminal regime is reached after around $100 \mathrm{~s}$ for this molar mass (cf. L4 in Figure 3) [29, 52].

The fact that only about $3 \%$ of the deformation induced by a creep deformation for $t_{0}=4150 \mathrm{~s}$ recoverable (Figure 3), illustrates that this anomalous behavior is not the consequence of a network, as in that case the viscous part of the deformation (about 97\%) would be much smaller in comparison to the elastic part (ideally 0\%) [53]. In single-phase melts besides cross-linking, only a high molecular component is known to be able to elevate $J_{\mathrm{e}}$ to a level above $10^{-2} \mathrm{~Pa}^{-1}[46,54]$.

However, the presence of such a high molecular component in F18G can be excluded, as such a high molecular component would certainly be detected by $S E C-M A L L S$, which reacts very sensitively towards high molecular components even in very small concentrations.

\subsubsection{Viscoelastic and thermorheological properties}

When looking at dynamic-mechanical data, for unshifted storage moduli $G^{\prime}(\omega)$, the data at different temperatures seem to converge to a common curve for $\omega<0.03 \mathrm{~s}^{-1}$ being indicated as the dashed line in Figure 4. This line has a slope of about 1, which is the terminal slope of $G^{\prime \prime}(\omega)$, but not of $G^{\prime}(\omega)$. Surprisingly, this line is almost temperature independent. The curves do not fall perfectly on the dashed line because of a small temperature dependence (the data at $230^{\circ} \mathrm{C}$ is right of the line, while the data at $110^{\circ} \mathrm{C}$ is left of it). It is not possible to find reliable shift factors, as this bend in the data, being an 


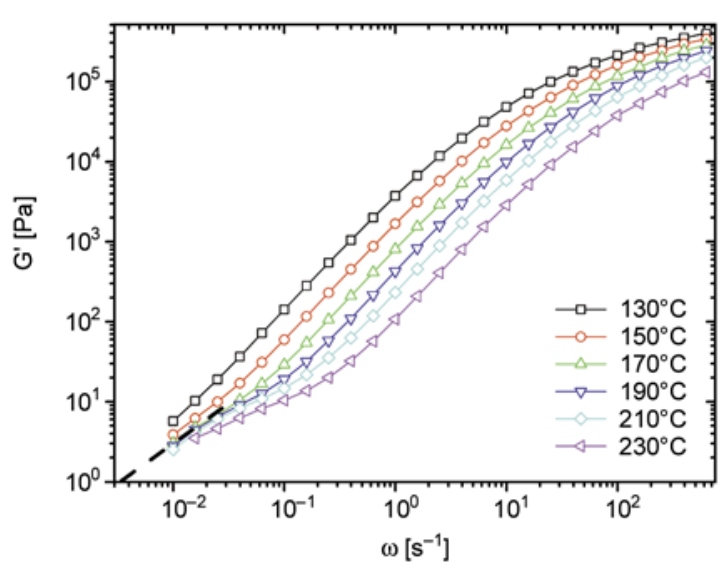

Figure 4. Storage moduli $G^{\prime}(\omega)$ of F18G

additional relaxation mode, is only partially covered by the dynamic-mechanical test.

When shifting the data obtained for F18G between 130 and $230^{\circ} \mathrm{C}$ a pseudo-master curve can be constructed for $G^{\prime}\left(a_{\mathrm{T}^{*}} \omega\right)$ and $G^{\prime \prime}\left(a_{\mathrm{T}} \cdot \omega\right)>30 \mathrm{~Pa}$ (Figure 5). The crossover frequency $\omega \mathrm{c}$ is around $40 \mathrm{~s}^{-1}$, which corresponds very nicely to the scaling law between the characteristic relaxation time $\lambda\left(=1 / \omega_{\mathrm{c}}\right)$ that has been previously established for HDPE [38]. However, it also becomes immediately obvious that the moduli of F18G are lower than, e.g., for the LLDPE L4. The difference between L4 and F18G lies in $G_{\mathrm{N}}^{0}$ and in $\omega_{\mathrm{c}}\left(\rightarrow M_{\mathrm{w}}\right)$ becomes obvious when shifting the data of L4 to the crossover frequency $\omega_{\mathrm{c}}\left(a_{\mathrm{T}}=0.5\right)$ and modulus $G_{\mathrm{c}}\left(b_{\mathrm{T}}=0.38\right)$ of F18G (thick lines in Figure 5a). Both datasets almost perfectly agree for $a_{\mathrm{T}} \cdot \omega>0.07 \mathrm{~s}^{-1}$. Hence, the two materials differ in the plateau modulus $G_{\mathrm{N}}^{0}$ by a factor of $\approx 2.5$. Because of the comonomer content of almost $w_{\mathrm{c}}=30 \mathrm{wt} . \%$, this is in accordance with previous findings [56]. It is actually quite surprising that the scaling of the characteristic

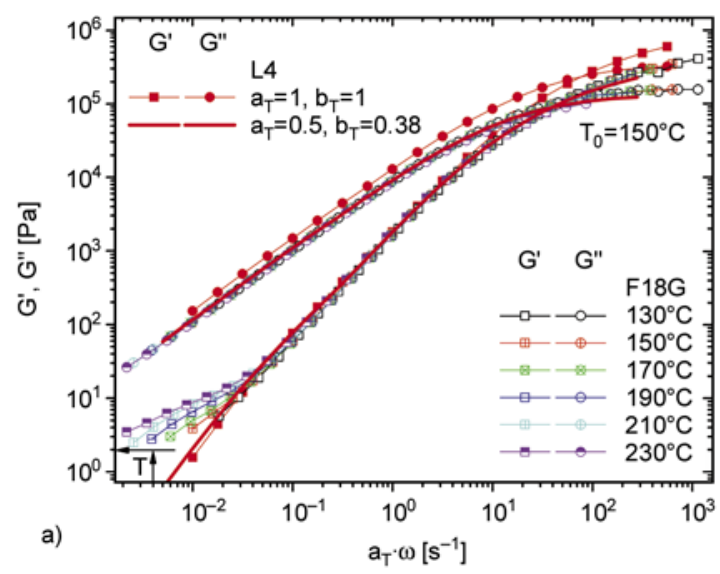

relaxation time $\lambda$ is fulfilled in the same way as HDPE despite the differences in chemical structure and $G_{\mathrm{N}}^{0}[56]$.

Self-evidently, it is not suggested to use the modulus shift $\left(b_{\mathrm{T}}\right)$ as an analytical tool. The shifted data of L4 instead provides excellent evidence that the shape of the rheological data of $\mathrm{F} 18 \mathrm{G}$ coincides very well with L4 for $G^{\prime}\left(a_{\mathrm{T}} \cdot \omega\right)$ and $G^{\prime \prime}\left(a_{\mathrm{T}} \cdot \omega\right)>$ $30 \mathrm{~Pa}$. The conclusion is that the relaxation behavior in this regime is unaffected, while the entanglement network is slightly looser (lower $G_{\mathrm{N}}^{0}$ ). The shift factor $a_{\mathrm{T}}=0.5$ for L4 used for this comparison is exactly the shift factor expected from the scaling law with molar mass $M_{\mathrm{w}}$ for the characteristic relaxation times established earlier for HDPE [38], which already indicates that the material doesn't behave the way expected from chemical composition, as, according to Chen et al. [56], a correction of the HDPE-scaling law has to be used. This discussion is given in detail in the conclusions section concerning the deviation from the $\eta_{0}-M_{\mathrm{w}}$-relation Figure $5 \mathrm{~b}$ shows that the elastic compliance $\left.J^{\prime}\left(a_{\mathrm{T}} \cdot \omega\right)>0.07 \mathrm{~s}^{-1}\right)$ of $\mathrm{F} 18 \mathrm{G}$ is higher than that for L4, but this is a consequence of the lower plateau modulus $G_{\mathrm{N}}^{0}$. This gives the opportunity to estimate the $J_{\mathrm{e}}^{0}$ of this material, which should be the steadystate elastic recovery compliance $J_{\mathrm{e}}^{0}$ of L4 divided by $b_{\mathrm{T}}$, i.e. $7 \cdot 10^{-5} \mathrm{~Pa}^{-1} / 0.38=1.8 \cdot 10^{-4} \mathrm{~Pa}^{-1}$ (according to the theory of rubber elasticity $J_{\mathrm{e}}^{0}=f \cdot G_{\mathrm{N}}^{0}$, where $f$ is a factor $\geq 2.5$ and dependent on molar mass distribution and molecular architecture) [12]. But as Figure $5 \mathrm{~b}$ shows, the upturn for $J^{\prime}\left(a_{\mathrm{T}^{*}} \omega<\right.$ $\left.0.07 \mathrm{~s}^{-1}\right)$ is so significant that the real $J_{\mathrm{e}}^{0}$ is significantly above that value (cf. Figure 3 ). A normal LLDPE with the same comonomers content would show a behavior similar to the data of L4, shifted to

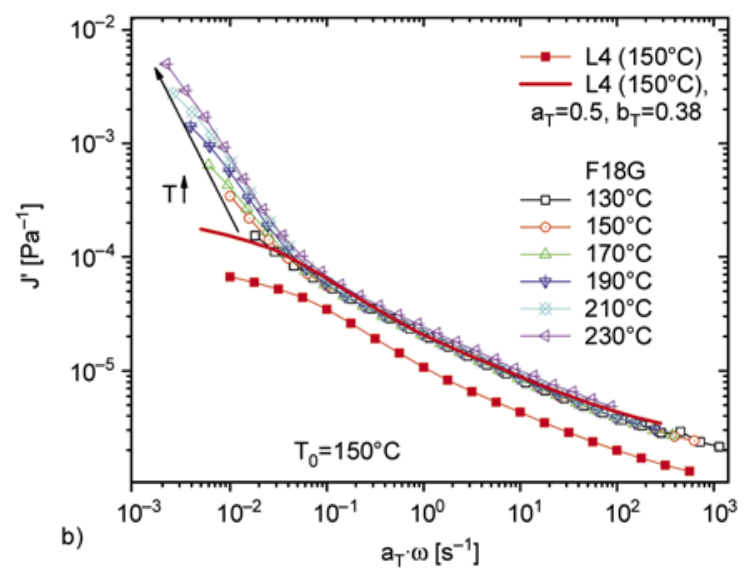

Figure 5. Pseudo-mastercurves of F18G in comparison to Butene-LLDPE L4. a) $G^{\prime}\left(a_{\mathrm{T}} \times \omega\right)$ and $G^{\prime \prime}\left(a_{\mathrm{T}} \times \omega\right)$, b) $J^{\prime}\left(a_{\mathrm{T}} \times \omega\right)$ 
the data of F18G using the same shift factors as already applied in Figure $5 \mathrm{a}\left(a_{\mathrm{T}}=0.5, b_{\mathrm{T}}=0.38\right)$.

Figure 5 shows clearly that $G^{\prime \prime}\left(a_{\mathrm{T}} \cdot \omega\right)$ is thermorheologically simple within the experimental accuracy, while $G^{\prime}\left(a_{\mathrm{T}^{*}} \omega\right)$ (and, thus, also $J^{\prime}\left(a_{\mathrm{T}^{*}} \omega\right)$ ) show a divergence below about $a_{\mathrm{T}^{*}} \omega=0.07 \mathrm{~s}^{-1}$. The upturn for $J^{\prime}\left(a_{\mathrm{T}} \cdot \omega<0.07 \mathrm{~s}^{-1}\right)$ is highly temperature dependent, such that it is no longer possible to call it a thermorheologically simple material.

Interestingly, the trend of the thermorheological complexity is exactly opposite to what is expected. Block-copolymers usually exhibit the largest thermorheological complexity at the lowest temperature, while F18G shows the largest deviations at the highest temperature $[9,14,15]$. Possible reasons for this behavior will be discussed later.

The relaxation spectra calculated according to the method of Stadler and Bailly [40, 41] given in Figure 6 lead to a highlighting of thermorheological complexity. It is obvious that the spectra of F18G can be divided into two distinctly different regimes. Above $H=6 \mathrm{~Pa}$, the spectrum looks like a typical example of a thermorheologically simple LLDPE, such as L4, also given in Figure 6a. Below $6 \mathrm{~Pa}$, a clear second process is present, which has almost no temperature dependence, as the spectra around $\tau=100 \mathrm{~s}$ are almost temperature independent.

An evaluation using the analysis method to determine the activation energy spectrum $E_{\mathrm{a}}(H)$ [31] clearly confirms this qualitative observation quantitatively (Figure 6b). The activation energy $E_{\mathrm{a}}(H)$ is constant $( \pm 2 \mathrm{~kJ} / \mathrm{mol})$ at the value of $39 \mathrm{~kJ} / \mathrm{mol} \mathrm{pub}-$ lished previously for this material for $H>6 \mathrm{~Pa}$ [19]. This behavior of $E_{\mathrm{a}}(H)=$ constant is typically found for all thermorheologically simple fluids like normal linear LLDPE and HDPE (the data of mHDPE

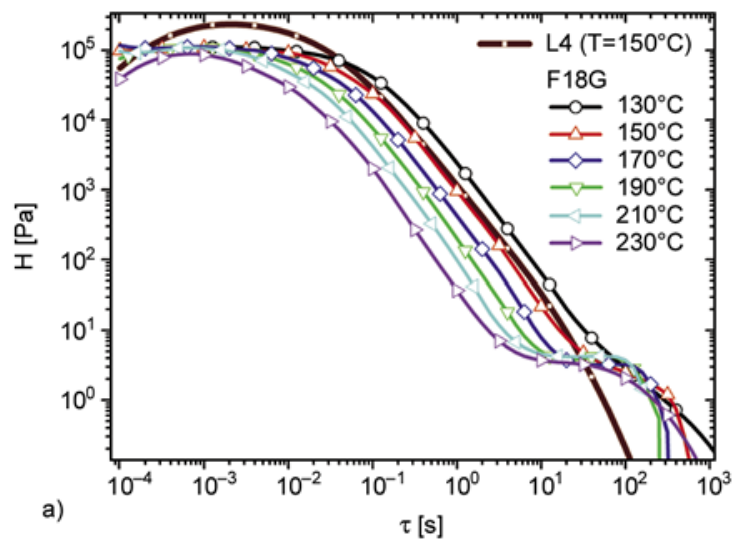

C4 [31] are also plotted in Figure 5b). Below this threshold, a very low and error-afflicted activation energy of around $5 \mathrm{~kJ} / \mathrm{mol}$ is found. This is a very strong effect, which has not been reported previously. LCB-mPE also show a thermorheological complexity; however, their activation energy increases, i.e., the opposite effect is observed.

Figure 6 shows the values of the recoverable compliances $J_{\mathrm{e}}$ after different creep times and elastic compliances $J^{\prime}$ at different angular frequencies of F18G at different temperatures. For a better comparability the time of the creep test divided by the shift factor $t_{0} / a_{\mathrm{T}}$ was set to be constant for all temperatures, i.e., the preceding creep tests were longer at low $T$ and shorter at high $T$. Essentially the same was done for the frequencies at which the elastic compliances were determined $\left(1 /\left(\omega \cdot a_{\mathrm{T}}\right)=\right.$ constant $)$. $J^{\prime}\left(1 /\left(\omega \cdot a_{\mathrm{T}}\right)=10 \mathrm{~s}\right)$ shows almost constant values; only the highest temperatures show a slightly higher elasticity. A constant value is the behavior expected for a conventional LLDPE. This finding makes sense, as $\omega \cdot a_{\mathrm{T}}=0.1 \mathrm{~s}^{-1}$ (c.f. Figure $4 \mathrm{~b}$ ) is the threshold between the normal LLDPE and the abnormal behavior of $\mathrm{F} 18 \mathrm{G}$ at lower frequencies $\omega \cdot a_{\mathrm{T}}$. At $\omega \cdot a_{\mathrm{T}}=0.01 \mathrm{~s}^{-1}$, there is a complete change in behavior: $J^{\prime}\left(\omega \cdot a_{\mathrm{T}}=0.01 \mathrm{~s}^{-1}\right)$ increases by a factor of 2 between 150 and $230^{\circ} \mathrm{C}$. The creep recovery tests with preceding creep times of $t_{0} / a_{\mathrm{T}}=1000$ and $10000 \mathrm{~s}$ are significantly higher in $J_{\mathrm{e}}$. When looking at the slope of $J_{\mathrm{e}}(T)$, it becomes obvious that the effect is smaller for these longer times than for $1 /\left(\omega \cdot a_{\mathrm{T}}\right)=10 \mathrm{~s}$, which corresponds to the time scale of the process causing the abnormal behavior (cf. Figure 5a). Because of the choice of $\omega \cdot a_{\mathrm{T}}=0.01 \mathrm{~s}^{-1}$, the position on the absolute time scale at which this process is probed depends on the temperature (the

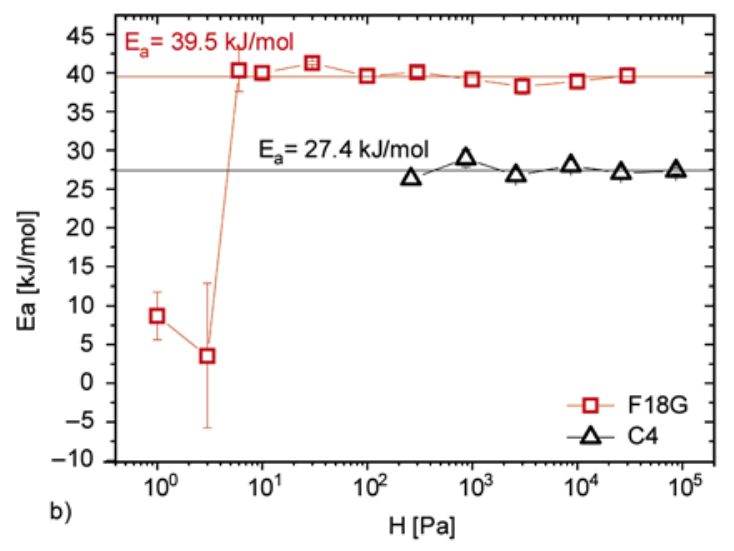

Figure 6. a) Relaxation spectra of F18G in comparison to Butene-LLDPE L4, b) activation energy spectrum 


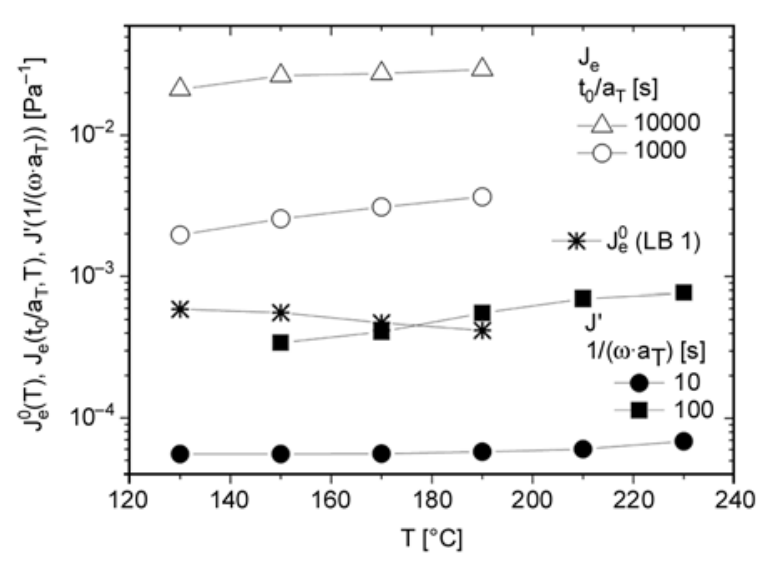

Figure 7. Recoverable compliances $J_{\mathrm{e}}$ after different creep times and elastic compliances $J^{\prime}$ at different angular frequencies of F18G as a function of temperature $T$ in comparison to LCB-mLLDPE LB1 [29]

shift factors $a_{\mathrm{T}}(T)$ are the shift factors valid for $H>6$ ). When the probing time is significantly larger than the characteristic time of this process, the differences are less pronounced than at the time of the process $\left(1 /\left(\omega \cdot a_{\mathrm{T}}\right)=100 \mathrm{~s}\right)$.

One might argue that this dependence of $J_{\mathrm{e}}$ on the temperature is the same as the $J_{\mathrm{e}}^{0}(T)$ dependence observed for LCB-mPE [29]. However, the temperature dependence of $J_{\mathrm{e}}^{0}$ for LCB-mPE is exactly opposite to $J_{\mathrm{e}}(T)$ for F18G (cf. * in Figure 7 for the data of LCB-mLLDPE LB 1 [29]). Hence, these two types of thermorheological complexity have a different physical basis.

\section{Discussion}

\subsection{Artifact?}

Of course, the first question a careful reader of this article would ask is, whether the unusual behavior of F18G could be an experimental artifact. To the author's mind, the following artifacts would be conceivable:

1. At low moduli, $\delta$ of some rheometers tends to become artificially large (which would produce exactly the same effect as shown)

2. Degradation of the sample

3. Remaining unincorporated comonomer

The error in $\delta$ (1.) can be excluded, because two different rheometers with different setups were used, which were both tested to deliver the expected results with respect to $\delta(\omega)$ for similar materials (e.g., L4, but also many more [29, 52]). Furthermore, the creep recovery compliance $J_{\mathrm{r}}(t)$ also shows this qualitative effect (for a quantitative comparison it would have to be proven that $J_{\mathrm{e}}$ is indeed $J_{\mathrm{e}}^{0}$ ) [57, 58]. It is highly unlikely that a problem with the rheometer setups used would produce the same results consistently for two different rheometers and two different test modes.

The thermal degradation of the sample (2.) can be excluded for several reasons. Firstly, a frequency sweep measurement was performed as a first test, and then the identical test was performed again after all other tests, so that any difference in molecular structure could have been spotted with that test. Secondly, tests have shown that the catalyst produces polymers that are very thermally stable (a product with slightly less comonomer but otherwise identical synthesis conditions was found to be stable for more than 1.5 weeks at $150^{\circ} \mathrm{C}$ ). Thirdly, a test at $130^{\circ} \mathrm{C}$ was performed before and after the test at $230^{\circ} \mathrm{C}$. Both tests at $130^{\circ} \mathrm{C}$ were identical within the usual reproducibility intervals of $\pm 5 \%$, even though the data at $230^{\circ} \mathrm{C}$ measured between the different runs at $130^{\circ} \mathrm{C}$ with the same sample is distinctly different. This points to the physical nature of the effect. It was also tested whether the domain/ phase structure can be distorted by heavy shear. It is possible to reduce the higher elasticity to a certain degree, although not completely, by significantly increasing the shear amplitude (Figure 8). Such shear susceptibility would be totally atypical of a chemical network.

It is, however, similar to effects found for blockcopolymer melts [59], where the rheological response can be changed by several decades for samples forming well-ordered cubic structures. The changes

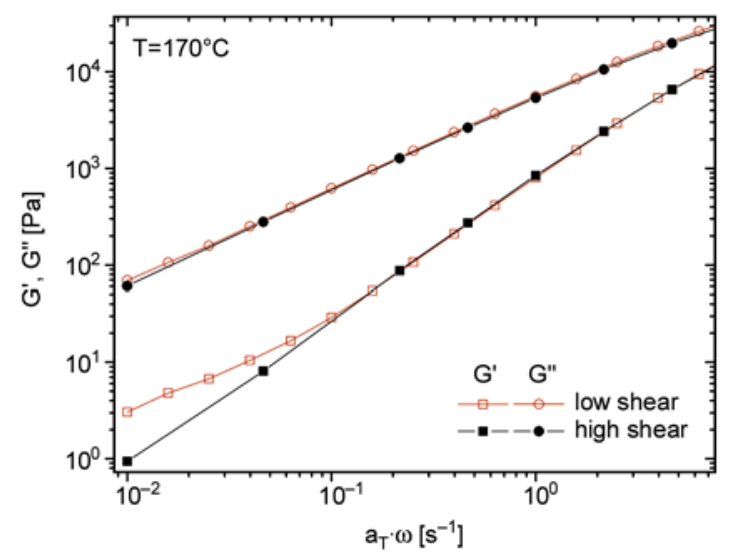

Figure 8. Comparison of the dynamic moduli of F18G at $170^{\circ} \mathrm{C}$ under low shear deformation $\left(\gamma_{0}<5 \%\right.$, open symbols) and high shear deformation $\left(\gamma_{0}(\omega=\right.$ $0.01 \mathrm{~s}^{-1}$ ) $\approx 80 \%$, filled symbols) 
given in Figure 8 for F18G are rather small in comparison, but that is not surprising considering that this material can achieve a much lower degree of order than regular diblock copolymers.

The question of the remaining unincorporated octadecene (3.) cannot be answered purely by rheology. GPC-MALLS did not show any significant amounts of a low molecular substance, which could cause that effect. Furthermore, it was found that heptadecane, which is very similar to the octadecene, has a tendency to evaporate quickly at $150^{\circ} \mathrm{C}$ [38]. Typically, a significant loss of heptadecane (30\%) was observed after 5 minutes. This was accompanied by a strong waxy smell in the laboratory, which lasted several hours. One can easily imagine that when keeping a sample of $\mathrm{F} 18 \mathrm{G}$ in the rheometer for 6 days at $150^{\circ} \mathrm{C}$, which was the longest measurement for this sample, no unincorporated octadecene would be left after that time. If the effect were caused by unincorporated octadecene, the behavior would change with time, but that was not the case here. Hence, a significant effect of unincorporated octadecene can be excluded.

Summarizing this section, experimental artifacts can be excluded, so that the observed effects must be due to a material property, which is discussed in the following.

\subsection{Origin of the unusual behavior}

\subsubsection{Phase separation}

The question is, if F18G is not long-chain branched, has a high molecular component, or is cross-linked, what is the origin of the thermorheological complexity?

Piel et al. [16] found that a high amount of long comonomers can lead to side-chain crystallization, being observable by both DSC and DMTA; in other words, the long comonomers tend to form a separate phase from the backbone in the solid state. For an octadecene-copolymers, (C18) this effect was found to be significantly smaller than for hexacosene-copolymers (C26), and barely observable for F18F (8C18 in Piel et al. [16]), the sample with the highest octadecene content in their study. The highest comonomer contents were around $3 \mathrm{~mol} \%$. The higher comonomer content of F18G of $n_{\mathrm{c}}=$ $4.5 \mathrm{~mol} \%$ will foster the phase separation even more, leading to a more phase separated structure. In the melt, neither F18F nor F26F both with about
3 mol\% comonomer content and octadecene and the longer hexacosene as comonomer, respectively, showed this abnormal behavior [19].

The reason why F26F and F18F show a phase separation in the solid state, although none can be detected in the melt, can only be that the driving forces for the phase separation are the crystallization kinetics. The thermodynamic explanation is that the methyl groups at the SCB- and chain ends cannot crystallize. This was proven by the synthesis of 'exact LLDPEs' [60], which have their shortchain branches at a defined position. In comparison to normal LLDPEs of the same comonomer content, their melting point is significantly higher and the crystallization peaks are narrower, i.e., the crystallites are more homogeneous and better built. This is a clear indicator that the SCB-ends are the moieties reducing the normal crystallization, because they do not fit in the crystal lattice. The consequence is that they stick out of the crystallites, thus, aligning them to some degree. This makes a secondary crystallization easier, which of course corresponds to a phase separation [16].

When crystallization driving forces are missing, e.g., in the melt, the phase separation becomes significantly less likely, and, therefore, needs more other driving forces to make it happen, e.g., a chemical difference. The high concentration of the SCBs in F18G increases the probability of different SCBends meeting each other, thus, forming a separate phase or domain (cf. Figure 9). Heindl et al. [24] recently suggested this type of behavior based on

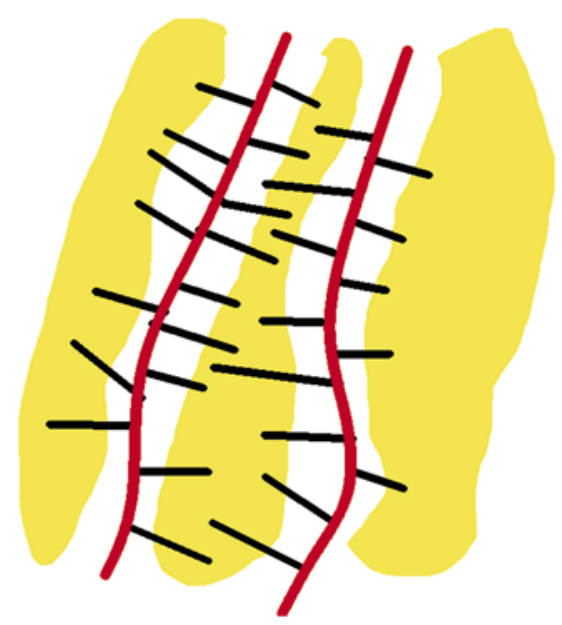

Figure 9. Sketch of the phase separated structure. Thick red lines: main chain, short, black lines: hexadecene side chains, yellow area: side chain phase 
their molecular dynamics simulations. The phase boundaries of these intermolecular phase separated polymers are not very sharp, as the molecule bridges the phase boundary, hence, they can be rather considered as domains [24]. However, the rheological behavior indicates that the driving forces for the phase separation are strong enough to distinctly modify the rheological properties. On one hand, they lower the zero shear-rate viscosity $\eta_{0}$ by a factor of 3 , but this is a consequence of the lower $G_{\mathrm{N}}^{0}$; the characteristic relaxation time $\lambda$ is unaffected. On the other hand, they introduce a relaxation mode into the polymer, which is very slow and differs in thermorheological behavior from that of the main chain.

\subsubsection{Effect of phase separation on zero shear-rate viscosity}

Finding a definite answer to the question why zero shear-rate viscosity, characteristic relaxation times, and plateau modulus do not follow the same scaling laws upon the introduction of the SCBs is not easy. The fact that F26F and F18G have almost the same weight comonomer content (around $30 \mathrm{wt} . \%$ ) but very different $\eta 0 / \eta 0$ lin means that the comonomer content alone cannot be made responsible for the differences. This also shows the limitations of the approach by Chen et al. [56] explaining the effect of comonomer on the rheological behavior, as their scaling laws don't apply to F18G. This alone suggests that F18G differs from conventional mLLDPEs.

When assuming a phase separation, several effects occur. On one hand, the entanglement network is loosened (see also Chen et al. [56]). A comparison with F26F suggests that the effect on $G_{\mathrm{N}}^{0}$ (and thus $\left.M_{\mathrm{e}}\right)$ is almost identical, i.e., $M_{\mathrm{e}}(\mathrm{F} 18 \mathrm{G}) \approx 850 \mathrm{kPa}$ as opposed to $1973 \mathrm{kPa}$ for L4. Hence, the entanglement network thinning is exactly as expected from the molecular data.

On the other hand, the characteristic relaxation time (e.g. the inverse crossover frequency) is almost unaffected by the comonomer content. According to Figure $5 \mathrm{a}$, the crossover frequencies of L4 and F18G differ by factor 0.5 , which is the ratio expected from looking at the molar masses $M_{\mathrm{w}}$ (without taking any comonomer effect into account). A comparison with Chen et al. [56] on the contrary would suggest a significantly higher factor, because the entanglement relaxation time $\tau_{\mathrm{e}}$ should longer by factor $\approx 50$ than L4. The experimental data of F18G (the $\omega_{\mathrm{c}}$-ratio of L4 and F18G is 0.5 as expected from the $M_{\mathrm{w}}$-ratio), however, suggests that $\tau \mathrm{e}$ is unaffected by the comonomers, while Chen et al. [56] suggest an increase.

This difference is quite puzzling, but can be rationalized the following way. The comonomers don't contribute to the entanglement network and, hence, the fact that they are in another phase doesn't influence the entanglement network. The 'slowing down' of the entanglement motion by the hexadecane side chains, however, does not occur and, therefore, $\tau_{\mathrm{e}}$ is unaffected. In other words, the material behaves just like HDPE with respect to the characteristic relaxation time $\lambda$ or $1 / \omega_{\mathrm{c}}$. Because, $\eta_{0}$ is proportional to the product of $G_{\mathrm{N}}^{0}$ and the terminal relaxation time (or $1 / \omega_{\mathrm{c}}$ ), a lowering of the plateau modulus by factor 3 , which (in contrast to single phase LLDPEs) is not balanced by a lowering of $\omega_{c}$ by the same factor, the zero shear-rate viscosity $\eta_{0}$ is decreased to $30 \%$ of its expected value.

This decrease is predicted, when taking Chen et al. [56] into account. Based on the higher monomer molar mass, they predict that $\tau_{\mathrm{e}}$ of F18G should be higher by factor 50 , which when taking the exponent of 3.6 into account, is a factor of 3 with respect to $\omega_{\mathrm{c}}$.

\subsubsection{Effect of the side chains on the low frequency properties}

Looking at the hexadecane side chains as separate entities is not cogent, as an unperturbed octadecene chain would have a main relaxation time in the range of around $5 \cdot 10^{-10} \mathrm{~s}$ (calculated from the assumption that the plateau modulus $G_{\mathrm{N}}^{0}$ of PE is around $2 \mathrm{MPa}$ and the zero shear-rate viscosity $\eta_{0}$ of pure octadecene is around $1 \mathrm{mPa} \cdot \mathrm{s}$ at $150^{\circ} \mathrm{C}$ [38]). Even when assuming that the incorporation of octadecene as side chains leads to a significant lengthening of the main relaxation time, it is very unlikely that its characteristic relaxation time is shifted by 10 to 11 orders of magnitude, from $5 \cdot 10^{-10} \mathrm{~s}$ to about $5 \mathrm{~s}\left(\omega \approx 0.02 \mathrm{~s}^{-1}\right)$. Also, this would not explain the low $E_{\mathrm{a}}$ of this process. Van Ruymbeke et al. [61] and Kapnistos et al. [62] found that pom-poms and combs with unentangled arms do not significantly affect the arms; i.e., the molecules behave like linear chains with a slightly lengthened 
relaxation time scale. Chen et al. [56] found the same for LLDPE. Thus, the extra relaxation mode cannot be caused by the main relaxation time of the hexadecane side chains.

As the hexadecane-side chains $\left(\mathrm{C}_{16}\right)$ are certainly unentangled (the entanglement molar mass of $\mathrm{PE}$ is reported to be around $1000 \mathrm{~g} / \mathrm{mol}=70 \mathrm{CH}_{2}$ [63]), they do not lend themselves to acting as long-chain branches. The rheological response would also look distinctly different in this case, and the activation energy would be significantly higher in the terminal regime.

A high molecular component would also not lead to a thermorheological complexity, as long as the chemical structure is not changing distinctly as a function of molar mass, which would be also very unlikely from a reaction kinetics point-of-view. Furthermore, it would have been detected by $S E C$ MALLS.

The most likely explanation is that the long-time relaxation mode is caused by the presence of intramolecular phase separation, as samples with sizable amounts of long short-chain branches are known to tend to phase separate, which is a consequence of the immiscibility of ethene- $a$-olefin copolymers of different side-chain contents [7, 8]. That is, the long short-chain branches behave as though independent, trying to separate themselves from their own backbone, thus leading to a separate phase, which can crystallize separately as well, if they are long enough [16].

This conclusion is supported by the previous finding that the steady-state elastic recovery compliances $J_{\mathrm{e}}^{0}$ of mLLDPEs with long comonomers are significantly higher than for short comonomers [51]. The higher $J_{\mathrm{e}}^{0}$ can be interpreted as the influence of the long side chains leading to a very weak intra-chain phase separation - the same effect as for F18G but significantly weaker.

\section{Possible reason for the different temperature dependence of the thermorheological complexity}

When comparing the chemical structures of F18G to the block-copolymers characterized in detail frequently, three important differences become obvious:

- F18G is a random copolymer with relatively long side chains, which are, however, distinctly below the entanglement molar mass $M_{\mathrm{e}}$ (less than 25\%). The block copolymers, characterized so far, are much higher in their block length than the side chains of F18G.

- F18G is a random copolymer, which can be considered to be a comb with short arms, blockcopolymers typically contain only one A- and one B-block.

- The chemical difference in F18G is very small. Effectively, the main chemical difference is the $\mathrm{CH}_{3}$-endgroup. Block-copolymers, however, typically contain two distinctly different comonomers, e.g. styrene and butadiene. However, also polymers with small chemical differences, e.g. the ethylene/octene-block octene might exhibit a clear phase separation although not as well ordered.

These three differences in chemical structure mean that

- The driving forces for phase separation are lower for F18G than for most block copolymers characterized so far, because the chemical difference is very small.

- The polymer does not contain an A- and a Bblock, but an A-main chain and, on weight average, approximately $160 \mathrm{~B}$-blocks as side chains, which is less than $16 \mathrm{C}$ each. Most probably the separated domain does not involve the complete side chain but only the 'outer' half.

The direct consequence is that the sample contains only a weakly separated structure, which, however, has a very high surface area and many chains crossing the surface. Hence, the sample has some similarities with a surfactant. Self-evidently, the small B-domains will coalesce and, thus, form larger domains or phases.

One striking feature of sample F18G in comparison to the block copolymers characterized so far is that the temperature dependence is inverse to the other samples. When we consider the differences in chemical structure, it becomes obvious that the different behavior must originate from the small chemical difference and the short blocks, i.e., the high surface area.

The most logical conclusion is the following. At low temperature, the side chains are less able to form a separate phase, because the solubility in the A-phase is low. So there is a sharp interface, which only slightly coalesces and the B-domains are 
small. When increasing the temperature, the miscibility increases. This has two effects. The degree of phase separation becomes smaller, but on the other hand the higher miscibility increases the thickness of the interface.

The rheological data has clearly demonstrated that the second effect is stronger. Because previously characterized block-copolymers had significantly larger blocks, this effect is not observed as the concentrations of chains passing through the surface is not as high as for F18G.

\section{Conclusions}

This article has shown evidence of a very unusual behavior of the special mLLDPE F18G. At low frequencies a clear secondary process becomes obvious, which is essentially unchanged by temperature, making it stronger at high temperatures. This leads to a decrease of the activation energy $E_{\mathrm{a}}$ as a function of relaxation strength $H$ below $H=6 \mathrm{~Pa}$. Also an increase of the elastic recovery compliance $J_{\mathrm{e}}$ with increasing $T$ was found. Both effects are opposite to the typical behavior of long-chain branched $\mathrm{PE}$, and it was, therefore, concluded that long-chain branches are not responsible for this behavior.

The sample F18G indeed shows a weak phase separation leading to a novel kind of thermorheological complexity, previously unknown for single phase melts. However, it is quite similar to the order/disorder transition for diblock copolymers [9].

The driving forces for this phase separation are the difference in chemical potential between $\mathrm{CH}_{3}$ - and $-\mathrm{CH}_{2}-$ groups and the large length and high molar fraction of the octadecene (i.e., the hexadecane side chains).

The fact that a special comonomer, as well as a relatively high concentration of that comonomer, is needed to cause this effect, and furthermore, that it is relatively weak, constitute the proffered explanation as to why it has not been discovered previously. The high interface and the weak chemical differences lead to an inversion of the usual temperature dependence found in block copolymers.

\section{Acknowledgements}

The author would like to thank the German Research Foundation and the Sanhak Industry-University Cooperation Fund for financial support. The synthesis of F18G is acknowledged to Dr. B. Arikan-Conley, group of Prof. Dr. W. Kaminsky (University Hamburg, Germany). Also the input from Prof. Dr. H. Münstedt, Dr. J. Resch, Dr. J. Kaschta, and Mrs. I. Herzer (Friedrich-Alexander University Erlangen-Nürnberg, Germany) concerning the measurements and their interpretation provided a valuable base for this article.

\section{References}

[1] Ferry J. D.: Viscoelastic properties of polymers. John Wiley and Sons, New York (1980).

[2] Sperling L. H.: Introduction to polymer science. Wiley, New York (2006).

[3] Rajasekaran J. J., Curro J. G., Honeycutt J. D.: Theory for the phase behavior of polyolefin blends: Application to the polyethylene/isotactic polypropylene blend. Macromolecules, 28, 6843-6853 (1995).

DOI: $10.1021 / \mathrm{ma} 00124 \mathrm{a} 020$

[4] Tashiro K., Stein R. S., Hsu S. L.: Cocrystallization and phase segregation of polyethylene blends. 1. Thermal and vibrational spectroscopic study by utilizing the deuteration technique. Macromolecules, 25, 18011808 (1992). DOI: $10.1021 / \mathrm{ma} 00032 \mathrm{a} 029$

[5] Bousmina M.: Effect of interfacial tension on linear viscoelastic behavior of immiscible polymer blends. Rheologica Acta, 38, 251-254 (1999).

DOI: $10.1007 / \mathrm{s} 003970050175$

[6] Fan Z. G. J., Williams M. C., Choi P.: A molecular dynamics study of the effects of branching characteristics of LDPE on its miscibility with HDPE. Polymer, 43, 1497-1502 (2002).

DOI: $10.1016 / \mathrm{S} 0032-3861(01) 00730-3$

[7] Godehardt R., Rudolph S., Lebek W., Goerlitz S., Adhikari R., Allert E., Giesemann J., Michler G. H.: Morphology and micromechanical behavior of blends of ethene/1-hexene copolymers. Journal of Macromolecular Science: Physics, 38, 817-835 (1999).

[8] Adhikari R., Godehardt R., Lebek W., Frangov S., Michler G. H., Radusch H-J., Calleja F. J. B.: Morphology and micromechanical properties of ethylene/1-octene copolymers and their blends with high density polyethylene. Polymers for Advanced Technologies, 16, 156-166 (2005).

DOI: $10.1002 /$ pat.578

[9] Bates F. S., Rosedale J. H., Fredrickson G. H.: Fluctuation effects in a symmetric diblock copolymer near the order-disorder transition. Journal of Chemical Physics, 92, 6255-6270 (1990).

DOI: $10.1063 / 1.458350$ 
[10] Almdal K., Bates F. S., Mortensen K.: Order, disorder, and fluctuation effects in an asymmetric poly(ethylene-propylene)-poly(ethylethylene) diblock copolymer. Journal of Chemical Physics, 96, 9122-9132 (1992).

DOI: $10.1063 / 1.462221$

[11] Kossuth M. B., Morse D. C., Bates F. S.: Viscoelastic behavior of cubic phases in block copolymer melts. Journal of Rheology, 43, 167-196 (1999).

DOI: $10.1122 / 1.550981$

[12] Dealy J., Larson R. G.: Structure and rheology of molten polymers - From structure to flow behavior and back again. Munich, Hanser (2006).

[13] Park H. E., Dealy J., Marchand G. R., Wang J., Li S., Register R. A.: Rheology and structure of molten, olefin multiblock copolymers. Macromolecules, 43, 6789-6799 (2010).

DOI: $10.1021 / \mathrm{ma1} 012122$

[14] Gaur U., Wunderlich B.: Study of microphase separation in block co-polymers of styrene and alphamethylstyrene in the glass-transition region using quantitative thermal-analysis. Macromolecules, 13, 1618-1625 (1980).

[15] Leibler L.: Theory of microphase separation in block copolymers. Macromolecules, 13, 1602-1617 (1980). DOI: $10.1021 / \mathrm{ma} 60078 \mathrm{a} 047$

[16] Piel C., Starck P., Seppälä J. V., Kaminsky W.: Thermal and mechanical analysis of metallocene-catalyzed ethene- $\alpha$-olefin copolymers: The influence of the length and number of the crystallizing side chains. Journal of Polymer Science Part A: Polymer Chemistry, 44, 1600-1612 (2006).

DOI: $10.1002 /$ pola.21265

[17] Stadler F. J., Takahashi T., Yonetake K.: Lattice sizes, crystallinities, and spacing between amorphous chains characterization of ethene-/ $\alpha$-olefin copolymers with various comonomers and comonomer contents measured by wide angle X-ray scattering. e-Polymers, no.40 (2009).

[18] Stadler F. J., Takahashi T., Yonetake K.: Crystal lattice of ethene-/ $\alpha$-olefin copolymers with various long comonomers (C8-C26) measured by wide angle X-ray diffraction. Macromolecular Chemistry and Physics, in press (2011).

[19] Stadler F. J., Takahashi T., Yonetake K.: Crystallite dimensions - characterization of ethene-/ $\alpha$-olefin copolymers with various comonomers and comonomer contents measured by small- and wide angle X-ray scattering. e-Polymers, no.41 (2009).

[20] Kessner U., Kaschta J., Stadler F. J., Le Duff C. S., Drooghaag X., Münstedt H.: Thermorheological behavior of various short- and long-chain branched polyethylenes and their correlations with the molecular structure. Macromolecules, 43, 7341-7350 (2010). DOI: $\underline{10.1021 / \mathrm{ma1} 00705 f}$
[21] Palierne J. F.: Linear rheology of viscoelastic emulsions with interfacial tension. Rheologica Acta, 29, 204-214 (1990).

DOI: $10.1007 / \mathrm{BF} 01331356$

[22] Handge U. A., Okamoto K., Münstedt H.: Recoverable deformation and morphology after uniaxial elongation of a polystyrene/linear low density polyethylene blend. Rheologica Acta, 46, 1197-1209 (2007).

DOI: $10.1007 / \mathrm{s} 00397-007-0208-5$

[23] Heindl M., Sommer M. K., Münstedt H.: Morphology development in polystyrene/polyethylene blends during uniaxial elongational flow. Rheologica Acta, 44, 55-70 (2004).

DOI: $10.1007 /$ s00397-004-0372-9

[24] Capodagli J., Lakes R.: Isothermal viscoelastic properties of PMMA and LDPE over 11 decades of frequency and time: a test of time-temperature superposition. Rheologica Acta, 47, 777-786 (2008).

DOI: $10.1007 / \mathrm{s} 00397-008-0287-y$

[25] Carella J. M., Gotro J. T., Graessley W. W.: Thermorheological effects of long-chain branching in entangled polymer melts. Macromolecules, 19, 659-667 (1986).

DOI: $10.1021 / \mathrm{ma} 00157 \mathrm{a} 031$

[26] Laun H. M.: Orientation of macromolecules and elastic deformations in polymer melts. Influence of molecular structure on the reptation of molecules. Progress in Colloid Polymer Science, 75, 111-139 (1987). DOI: $10.1007 / \mathrm{BFb} 0109414$

[27] Keßner U., Kaschta J., Münstedt H.: Determination of method-invariant activation energies of long-chain branched low-density polyethylenes. Journal of Rheology, 53, 1001-1016 (2009).

DOI: $10.1122 / 1.3124682$

[28] Keßner U., Münstedt H.: Thermorheology as a method to analyze long-chain branched polyethylenes. Polymer, 51, 507-513 (2009).

DOI: $10.1016 /$ j.polymer.2009.11.005

[29] Resch J. A., Stadler F. J., Kaschta J., Münstedt H.: Temperature dependence of the linear steady-state shear compliance of linear and long-chain branched polyethylenes. Macromolecules, 42, 5676-5683 (2009). DOI: $10.1021 / \mathrm{ma} 9008719$

[30] Wood-Adams P. M., Costeux S.: Thermorheological behavior of polyethylene: Effects of microstructure and long chain branching. Macromolecules, 34, 62816290 (2001). DOI: $10.1021 / \mathrm{ma} 0017034$

[31] Stadler F. J., Kaschta J., Münstedt H.: Thermorheological behavior of various long-chain branched polyethylenes. Macromolecules, 41, 1328-1333 (2008). DOI: $10.1021 / \mathrm{ma} 702367 \mathrm{a}$

[32] Stadler F. J., Arikan B., Kaschta J., Rulhoff S., Kaminsky W.: Long-chain branch formation in syndiotactic polypropene induced by vinyl chloride. Macromolecular Chemistry and Physics, 211, 1472-1481 (2010). DOI: $\underline{10.1002 / \mathrm{macp} .200900688}$ 
[33] Stange J., Wächter S., Kaspar H., Münstedt H.: Linear rheological properties of the semi-fluorinated copolymer tetrafluoroethylene-hexafluoropropylene-vinylidenfluoride (THV) with controlled amounts of longchain branching. Macromolecules, 40, 2409-2416 (2007). DOI: $10.1021 / \mathrm{ma} 0626867$

[34] Kaminsky W., Piel C., Scharlach K.: Polymerization of ethene and longer chained olefins by metallocene catalysis. Macromolecular Symposia, 226, 25-34 (2005).

DOI: $10.1002 /$ masy.200550803

[35] Piel C., Stadler F. J., Kaschta J., Rulhoff S., Münstedt H., Kaminsky W.: Structure-property relationships of linear and long-chain branched metallocene high-density polyethylenes characterized by shear rheology and SEC-MALLS. Macromolecular Chemistry and Physics, 207, 26-38 (2006).

DOI: $10.1002 /$ macp. 200500321

[36] Stadler F. J., Piel C., Klimke K., Kaschta J., Parkinson M., Wilhelm M., Kaminsky W., Münstedt H.: Influence of type and content of various comonomers on long-chain branching of ethene/ $\alpha$-olefin copolymers. Macromolecules, 39, 1474-1482 (2006).

DOI: $10.1021 / \mathrm{ma} 0514018$

[37] Klimke K., Parkinson M., Piel C., Kaminsky W., Spiess H-W., Wilhelm M.: Optimisation and application of polyolefin branch quantification by melt-state ${ }^{13} \mathrm{C}$ NMR spectroscopy. Macromolecular Chemistry and Physics, 207, 382-395 (2006).

DOI: $10.1002 /$ macp. 200500422

[38] Stadler F. J., Piel C., Kaschta J., Rulhoff S., Kaminsky W., Münstedt H.: Dependence of the zero shear-rate viscosity and the viscosity function of linear high-density polyethylenes on the mass-average molar mass and polydispersity. Rheologica Acta, 45, 755-764 (2006).

DOI: $10.1007 / \mathrm{s} 00397-005-0042-6$

[39] Gabriel C., Kaschta J., Münstedt H.: Influence of molecular structure on rheological properties of polyethylenes I. Creep recovery measurements in shear. Rheologica Acta, 37, 7-20 (1998).

DOI: $10.1007 / \mathrm{s} 003970050086$

[40] Stadler F. J., Bailly C.: A new method for the calculation of continuous relaxation spectra from dynamicmechanical data. Rheologica Acta, 48, 33-49 (2009). DOI: $10.1007 / \mathrm{s} 00397-008-0303-2$

[41] Stadler F. J.: Effect of incomplete datasets on the calculation of continuous relaxation spectra from dynamicmechanical data. Rheologica Acta, 49, 1041-1057 (2010). DOI: 10.1007/s00397-010-0479-0

[42] Stadler F. J., Kaschta J., Münstedt H.: Dynamicmechanical behavior of polyethylenes and ethene- $\alpha-$ olefin-copolymers. Part I. $\alpha^{\prime}$-relaxation. Polymer, 46, 10311-10320 (2005).

DOI: $10.1016 /$ j.polymer.2005.07.099
[43] Pérez E., Benavente R., Quijada R., Narváez A., Galland G. B.: Structure characterization of copolymers of ethylene and 1-octadecene. Journal of Polymer Science Part B: Polymer Physics, 38, 1440-1448 (2000). DOI: $10.1002 /($ SICI) 1099-0488(20000601)38:11<1440 $\because$ AID-POLB40>3.0.CO;2-O

[44] Wood-Adams P. M., Dealy J. M., deGroot A. W., Redwine O. D.: Effect of molecular structure on the linear viscoelastic behavior of polyethylene. Macromolecules, 33, 7489-7499 (2000).

DOI: $10.1021 / \mathrm{ma99} 1533 \mathrm{z}$

[45] Stadler F. J., Piel C., Kaminsky W., Münstedt H.: Rheological characterization of long-chain branched polyethylenes and comparison with classical analytical methods. Macromolecular Symposia, 236, 209-218 (2006).

DOI: $10.1002 /$ masy.200690057

[46] Gabriel C., Münstedt H.: Influence of long-chain branches in polyethylenes on linear viscoelastic flow properties in shear. Rheologica Acta, 41, 232-244 (2002).

DOI: $10.1007 / \mathrm{s} 00397-001-0219-6$

[47] Gabriel C., Kokko E., Löfgren B., Seppälä J., Münstedt H.: Analytical and rheological characterization of long-chain branched metallocene-catalyzed ethylene homopolymers. Polymer, 43, 6383-6390 (2002).

DOI: $10.1016 / \mathrm{S} 0032-3861(02) 00564-5$

[48] He C., Costeux S., Wood-Adams P.: A technique to infer structural information for low level long chain branched polyethylenes. Macromolecules, 45, 37473754 (2004).

DOI: $10.1016 /$ j.polymer.2004.03.085

[49] Arikan B., Stadler F. J., Kaschta J., Münstedt H., Kaminsky W.: Synthesis and characterization of novel ethene-graft-ethene/propene copolymers. Macromolecular Rapid Communications, 28, 1472-1478 (2007). DOI: $10.1002 /$ marc. 200700161

[50] Wang J-S., Knox J. R., Porter R. S.: Steady-state and dynamic rheology of poly(1-olefin) melts. Polymer, 16, 1709-1719 (1978). DOI: $10.1002 /$ pol.1978.180161001

[51] Stadler F. J., Münstedt H.: Terminal viscous and elastic properties of linear ethene/ $\alpha$-olefin copolymers. Journal of Rheology, 52, 697-712 (2008).

DOI: $10.1122 / 1.2892039$

[52] Wolff F., Resch J. A., Kaschta J., Münstedt H.: Comparison of viscous and elastic properties of polyolefin melts in shear and elongation. Rheologica Acta, 49, 95-103 (2010).

DOI: $10.1007 / \mathrm{s} 00397-009-0396-2$

[53] Schmidt M., Münstedt H.: On the elastic properties of model suspensions as investigated by creep recovery measurements in shear. Rheologica Acta, 41, 205-210 (2002).

DOI: $10.1007 / \mathrm{s} 003970100206$ 
[54] Plazek D. J., Echeverria I.: Don’t cry for me Charlie Brown, or with compliance comes comprehension. Journal of Rheology, 44, 831-841 (2000).

DOI: $10.1122 / 1.551117$

[55] Gabriel C.: Einfluss der molekularen Struktur auf das viskoelastische Verhalten von Polyethylenschmelzen. Shaker-Verlag, Aachen (2001).

[56] Chen X., Stadler F. J., Münstedt H., Larson R. G.: Method for obtaining tube model parameters for commercial ethene/ $\alpha$-olefin copolymers. Journal of Rheology, 54, 393-406 (2010).

DOI: $10.1122 / 1.3305721$

[57] Kaschta J., Schwarzl F. R.: Calculation of discrete retardation spectra from creep data: 1 . Method. Rheologica Acta, 33, 517-529 (1994).

DOI: $10.1007 / \mathrm{BF} 00366336$

[58] Kaschta J., Schwarzl F. R.: Calculation of discrete retardation spectra from creep data: 2. Analysis of measured creep curves. Rheologica Acta, 33, 530-541 (1994).

DOI: $\underline{10.1007 / \mathrm{BF} 00366337}$
[59] Sebastian J. M., Graessley W. W., Register R. A.: Steady-shear rheology of block copolymer melts and concentrated solutions: Defect-mediated flow at low stresses in body-centered-cubic systems. Journal of Rheology, 46, 863-879 (2002).

DOI: $10.1122 / 1.1475979$

[60] Rojas G., Berda E. B., Wagener K. B.: Precision polyolefin structure: Modeling polyethylene containing alkyl branches. Polymer, 49, 2985-2995 (2008).

DOI: $10.1016 /$ j.polymer.2008.03.029

[61] van Ruymbeke E., Kapnistos M., Vlassopoulos D., Huang T. Z., Knauss D. M.: Linear melt rheology of pom-pom polystyrenes with unentangled branches. Macromolecules, 40, 1713-1719 (2007).

DOI: $10.1021 / \mathrm{ma} 062487 \mathrm{n}$

[62] Kapnistos M., Vlassopoulos D., Roovers J., Leal L. G.: Linear rheology of architecturally complex macromolecules: Comb polymers with linear backbones. Macromolecules, 38, 7852-7862 (2005).

DOI: $10.1021 / \mathrm{ma} 050644 \mathrm{x}$

[63] Fetters L. J., Lohse D. J., Graessley W. W.: Chain dimensions and entanglement spacings in dense macromolecular systems. Journal of Polymer Science Part B: Polymer Physics, 37, 1023-1033 (1999). DOI: $10.1002 /($ SICI) 1099-0488(19990515)37:10<1023 ::AID-POLB7>3.0.CO;2-T 